Check for updates

Cite this: RSC Adv., 2019, 9, 37267

Received 3rd September 2019

Accepted 23rd October 2019

DOI: 10.1039/c9ra07032j

rsc.li/rsc-advances

\section{Blank experimental study on the determination of nitrogen and oxygen isotopes by chemical conversion method}

\author{
Yuhan Zong, (iD ab Jing $\mathrm{Hu}^{\mathrm{c}}$ Yadi Wang, ${ }^{\text {ab }}$ Hongliang Sun, ${ }^{\mathrm{d}}$ Yuliang $\mathrm{Li}^{\star \mathrm{ab}}$ \\ and Weiguo Liu $^{\mathrm{C}}$
}

\begin{abstract}
The reduction of nitrate to nitrous oxide by chemical conversion has the characteristics of simple operation and high sensitivity. Therefore, it is widely used in the pretreatment of nitrogen and oxygen isotopes. In this paper, a series of blank experiments were performed to determine various factors influencing the determination process for the chemical conversion method. To determine blank background values for reagents such as deionized water, $\mathrm{NaCl}$ and cadmium powder used in the experiment, the optimal experimental conditions of $\mathrm{NaN}_{3}, \mathrm{NaCl}$ and cadmium powder were determined to maximize the nitrate reduction rate. The results showed that $\mathrm{NaCl}$ was burned at $450{ }^{\circ} \mathrm{C}$ for 48 hours, and the placement time was not more than one day, which could minimize the pollution introduced by $\mathrm{NaCl}$. When $0.3 \mathrm{~g}$ of cadmium powder and $600 \mathrm{nmol}$ of $\mathrm{NaN}_{3}$ were added, the overall reduction efficiency reached $90 \%$. After measuring actual standard samples, the method demonstrated a good accuracy and applicability.
\end{abstract}

\section{Introduction}

Nitrogen is an important component for all living things, the primary limiting factor for the productivity of most terrestrial ecosystems and affects the global nitrogen cycle. Nitrate is an important nitrogen source in terrestrial and aquatic ecosystems. With the increase in fossil fuel combustion and agricultural activities, the importance of nitrate in atmospheric deposition, plants, soil and aquatic ecosystems has become the focus of environmental science and ecological research. $\cdot^{1-4}$ The isotopic composition of nitrogen in nitrate $\left(\delta^{15} \mathrm{~N}\right.$ and $\left.\delta^{18} \mathrm{O}\right)$ can provide valuable information to characterize the dominant sources of nitrate contamination. ${ }^{5}$ The nitrate stable isotope technique, with its tracer, indicator and integrative functions, has been widely used to study the dynamics and sources of nitrate in atmospheric deposition, aquatic ecosystems, soil and plants. ${ }^{6-10}$

With the development of testing technology, the latest methods for the determination of nitrogen and oxygen isotopes in nitrate are the chemical conversion method and biological conversion method. The biological conversion method has more requirements in the laboratory; the bacterial survival

\footnotetext{
${ }^{a}$ Key Laboratory of Subsurface Hydrology and Ecological Effects in Arid Region, Ministry of Education, Chang'an University, Xi'an 710054, China. E-mail: yulianglee@Hotmail.com; Tel: +86-29-82334853

${ }^{b}$ School of Environmental Science and Engineering, Chang'an University, Xi'an 710054, China

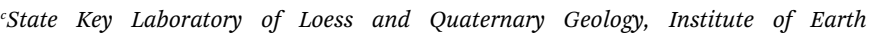
Environment, Chinese Academy of Sciences, Xi'an, China

${ }^{d}$ Chinese Academy for Environmental Planning, Beijing, 100012, China
}

conditions are strict and the survival rate is lower. ${ }^{11}$ However, chemical conversion is easy to operate and the mechanism is simple where nitrate is reduced to nitrous oxide in only two steps.

Lachouani et al. used vanadium chloride $\left(\mathrm{VCl}_{3}\right)$ as a reducing agent in the first step to convert $\mathrm{NO}_{3}{ }^{-}$into $\mathrm{NO}_{2}{ }^{-}$and sodium azide was used in the second step under acidic conditions to convert $\mathrm{NO}_{2}{ }^{-}$into $\mathrm{N}_{2} \mathrm{O} .^{12}$ However, this method could not determine the value of $\delta^{18} \mathrm{O}$ and the nitrate pollution in the second step of the reductant, sodium azide, led to a larger blank value for the entire method. McIlvin et al. reduced the nitrate to nitrite with sponge cadmium or active cadmium in the first step of the reduction process. ${ }^{13}$ The greatest advantage of this method is that it could simultaneously determine the nitrogen and oxygen isotope composition in nitrate. However, the preparation of sponge cadmium or active cadmium is complicated. Therefore, Tu et al. improved the azide method for the analysis of nitrate isotopes. ${ }^{14}$ In other words, $\mathrm{NO}_{3}{ }^{-}$was reduced to $\mathrm{NO}_{2}{ }^{-}$ using cadmium powder instead of sponge cadmium or active cadmium under an ultrasonic wave. In addition, the amount of the toxic azoic acid acetate buffer in the second reduction reaction was reduced to $1 / 100$ th the original trial amount. The method is simple in operation, short in preparation time and easy to establish. ${ }^{15}$

The results from Bell et al. showed that the background nitrate contamination introduced by different brands of $\mathrm{KCl}$ were different. ${ }^{16}$ However, in the chemical denitrification process, more chemical reagents such as $\mathrm{NaCl}, \mathrm{NaN}_{3}$, Cd power, etc. are used in the reagent preparation process. Different levels of nitrogen pollution are inevitable. Therefore, the background 
value of nitrogen introduced by the reagents during the chemical denitrification process could not be ignored. At present, there are few studies on reducing the influence of the blank background value on a nitrogen-oxygen stable isotope measurement by controlling the pretreatment method and chemical reagent process. ${ }^{17}$

Based on the above analysis, the blank value and reduction rate were studied using the modified azide method. More specifically, the blank value of each reagent was first measured. The experimental blank value was reduced by changing the $\mathrm{NaCl}$ placement time after firing and the purge time for the sodium azide acetate buffer. The amount of cadmium added, the addition of sodium azide and the reaction time in the nitrous oxide experimental conditions were optimized to ensure a high yield. ${ }^{18-21}$

In this paper, we examined the blank background values for $\mathrm{NaCl}, \mathrm{Cd}$ power and deionized water with the chemical denitrification method, determined the optimal experimental conditions for the method and established a good experimental basis for the subsequent detection of sample isotope values. By measuring the isotope value of the natural sample, it showed that the above method has good applicability. ${ }^{22}$

\section{Experimental}

\section{Sample analysis}

There were two main steps performed before determining the nitrogen and oxygen isotopes in the sample. ${ }^{\mathbf{1 4}}$ First, nitrate was reduced to nitrite by cadmium powder. Specifically, a sample containing $25 \mathrm{nmol}$ of nitrate was added to a $10 \mathrm{~mL}$ centrifuge tube, followed by dilution with deionized water to $5 \mathrm{~mL}$. NaCl was added to provide a final $\mathrm{Cl}^{-}$concentration of $5 \mathrm{M}$. Then, $0.3 \mathrm{~g}$ of Cd powder without pretreatment was added, followed by $0.1 \mathrm{~mL}$ of a $1 \mathrm{M}$ imidazole solution. The centrifuge tube was sealed, mixed, placed in an ultrasonic environment, sonicated at $40{ }^{\circ} \mathrm{C}$ for $2 \mathrm{~h}$ and allowed to stand at room temperature overnight after sonication. Second, sodium azide reduced nitrite to nitrous oxide. Specifically, $0.65 \mathrm{~g}$ of $\mathrm{NaN}_{3}$ in a $20 \mathrm{~mL}$ headspace bottle was added to $5 \mathrm{~mL}$ of deionized water in a fume hood and the mixture was shaken. Then, $5 \mathrm{~mL}$ of a $20 \%$ acetic acid solution was added for acidification. The solution was purified with the reagent at $70 \mathrm{~mL} \min ^{-1} \mathrm{~N}_{2}$ for $1.5 \mathrm{~h}$ (long needle air intake, short needle gas outlet) to remove the $\mathrm{N}_{2} \mathrm{O}$ gas in the solution. The supernatant was removed from the centrifuge tube in the $4 \mathrm{~mL}$ to $20 \mathrm{~mL}$ headspace bottle. The rubber plug and aluminum cover were installed. The above reaction was added to each headspace bottle with $0.2 \mathrm{~mL}$ of $\mathrm{NaN}_{3}$ buffer. The mixture was shaken for $30 \mathrm{~min}$ and the reaction was terminated by the addition of $0.4 \mathrm{~mL}$ of $10 \mathrm{M} \mathrm{NaOH}$. Lastly, a certain amount of gas in the upper part of the headspace bottle was injected into an isotope ratio mass spectrometer with an automatic preconcentration device to determine the nitrogen and oxygen isotope ratio of $\mathrm{N}_{2} \mathrm{O}$ in the gas sample.

\section{Experiment 1: effect of $\mathrm{NaCl}$ on its background $\mathrm{N}_{2} \mathrm{O}$ value}

To evaluate the background $\mathrm{N}_{2} \mathrm{O}$ value for $\mathrm{NaCl}$ caused by the firing temperature for $\mathrm{NaCl}$ and the time after firing, $\mathrm{NaCl}$ was pre-combusted at $450{ }^{\circ} \mathrm{C}$ and $550{ }^{\circ} \mathrm{C}$ for 48 hours in the muffle furnace. Then, $\mathrm{NaCl}$ was placed in a glass vacuum dryer for different days ( 1 to 6 days). The purpose of the pre-combusted $\mathrm{NaCl}$ was to remove any moisture and other impurities from the crystal.

\section{Experiment 2: effect of whether or not the supernatant was filtered on the second step of the reduction}

Since the experiment was performed two steps, the solution containing the cadmium powder obtained in the first step of the reduction process may have affected the second step reaction. The solution obtained in the first step was filtered to see if filtration had an effect on the experimental results. We chose two different types of filters, $0.2 \mu \mathrm{m}$ and $0.45 \mu \mathrm{m}$ hydrophilic filters.

\section{Experiment 3: effect of the $\mathrm{Cd}$ powder addition on the reduction efficiency of $\mathrm{NO}_{3}{ }^{-}$to $\mathrm{NO}_{2}{ }^{-}$}

In order to maximize the $\mathrm{NO}_{3}{ }^{-}$reduction yield, we checked the effect of the Cd powder addition on the reduction efficiency. In this experiment, except for the amount of Cd powder, all reaction conditions were the same as those in the previous experiment. Before this experiment, we compared the reduction rate of nitrate during the first step of the reduction process with several of the same experiments.

\section{Experiment 4: effect of the $\mathrm{NaN}_{3}$ purge time on its background $\mathrm{N}_{2} \mathrm{O}$ value and $\mathrm{NaN}_{3}$ on the reduction efficiency of $\mathrm{NO}_{2}{ }^{-}$to $\mathrm{N}_{2} \mathrm{O}$}

In the experiment, the sample was purged with a nitrogen gas flow to remove the nitrogen impurities in $\mathrm{NaN}_{3}$ and eliminate the negative pressure in the headspace bottle. To determine if the background $\mathrm{N}_{2} \mathrm{O}$ value for $\mathrm{NaN}_{3}$ was affected by its purge time, we tested four different times ( 0.5 hours, 1 hour, 1.5 hours and 2 hours). In the second reduction reaction step, $\mathrm{NO}_{2}$ was converted into $\mathrm{N}_{2} \mathrm{O}$ using the azide buffer. Because $\mathrm{NaN}_{3}$ is extremely toxic and volatile, reducing the amount of $\mathrm{NaN}_{3}$ is important for the experiment. Therefore, we implemented a program to test its minimum usage without affecting its results.

\section{Results and discussion}

\section{The whole blank composition of chemical conversion method}

Based on the above experimental methods, we first determined the blank composition of some major substances. These substances included deionized water (DIW), $\mathrm{NaCl}, \mathrm{Cd}$ and a total blank composition. The $m / z 44$ peak amplitude detected by the mass spectrometer indicated the $\mathrm{N}_{2} \mathrm{O}$ content in the substance (Fig. 1). Then, the value of the $\mathrm{m} / \mathrm{z} 44$ peak represented the ion signal strength and was based on the response value for $\mathrm{N}_{2} \mathrm{O}$. We analyzed the composition of the total blank during the experiment by measuring the $m / z 44$ peak. ${ }^{16}$ As shown in Fig. 1, a lack of attention to detail could result in different blank errors, even with the same operation. Therefore, we needed to refine the details of each step. If $\mathrm{NO}_{3}{ }^{-}$was not 


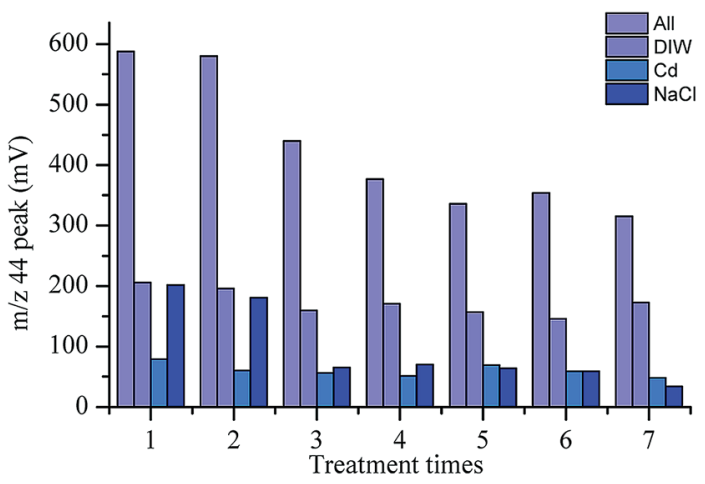

Fig. 1 Variation in the peak amplitude range $(\mathrm{m} / \mathrm{z} 44)$ for three main substances and the total blank composition.

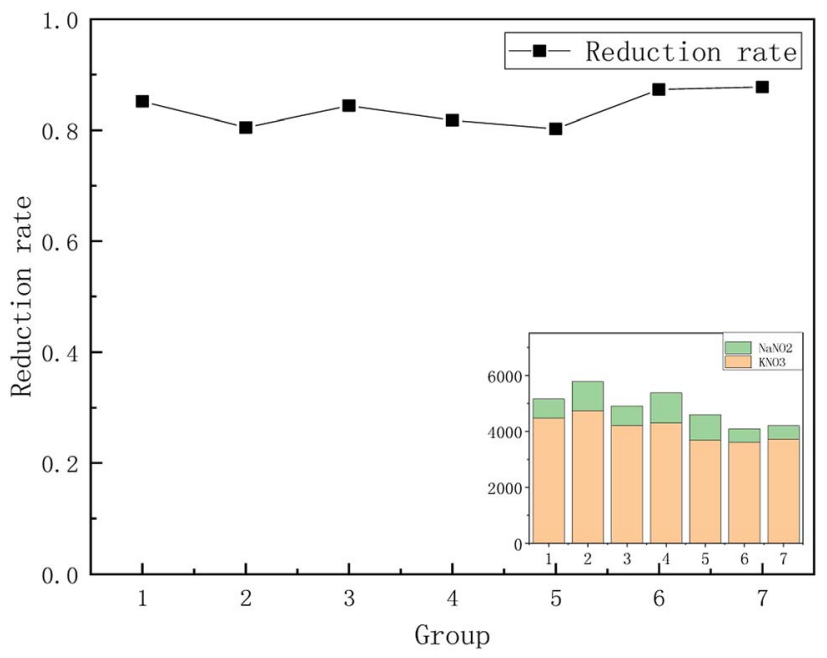

Fig. 2 Reduction rate for $\mathrm{NO}_{3}^{-}$to $\mathrm{NO}_{2}^{-}$. completely converted to $\mathrm{N}_{2} \mathrm{O}$, isotopic fractionation could be caused, resulting in measurement errors. Therefore, we needed to determine the conversion rate of nitrate. We calculated the reduction rate of nitrate by measuring the $m / z 44$ peak for $\mathrm{KNO}_{3}$ and $\mathrm{NaNO}_{2}$. After the calculation, we determined that the reduction rate of nitrate during the first step of the reduction was between $80 \%$ and $90 \%$ (Fig. 2 ).

\section{The exploration of $\mathrm{N}_{2} \mathrm{O}$ background value in $\mathrm{NaCl}$}

The $\mathrm{N}_{2} \mathrm{O}$ produced by the $\mathrm{NO}_{3}{ }^{-}$reduction was introduced into an isotope-ratio mass spectrometer. The $\mathrm{N}$ and $\mathrm{O}$ isotopic composition was measured for $\mathrm{N}_{2} \mathrm{O}$. The value for $\mathrm{N}_{2} \mathrm{O}$ was closely related to the measured isotope value. It was necessary to explore the $\mathrm{N}_{2} \mathrm{O}$ background value in the reagents used. We found that the blank value for deionized water in the first two experiments was about 200, which was higher than the other experimental values (150-170). This was because the blank value for deionized water in the first two experiments was relatively large after being added for a period of time. Therefore, deionized water was used immediately after receival. Then, the value for the $\mathrm{m} / \mathrm{z} 44$ peak in Cd ranged from 30 to 80 . In the previous experiment, we determined that $\mathrm{NaCl}$ had a greater impact on the background value (Fig. 1). Therefore, it made sense to explore the impact of $\mathrm{NaCl}$ on the blank value. In this experiment, the variation in the $\mathrm{m} / z 44$ peak for $\mathrm{NaCl}$ was larger and the difference was obvious. The minimum value was 33 and the maximum value was 202 . This indicated that although the blank for deionized water was relatively large, the influence of NaCl was the largest. ${ }^{18}$ This effect was minimized by making the standards and blanks in the same $\mathrm{NaCl}$ solution.

$\mathrm{NaCl}$ was analyzed by X-ray diffraction. As shown in Fig. 3, the content for the other impurities in the $\mathrm{NaCl}$ reagent was all below the normal range, which indicated that the higher $\mathrm{N}_{2} \mathrm{O}$ background value in $\mathrm{NaCl}$ was caused by operation and pretreatment during the experimental process.

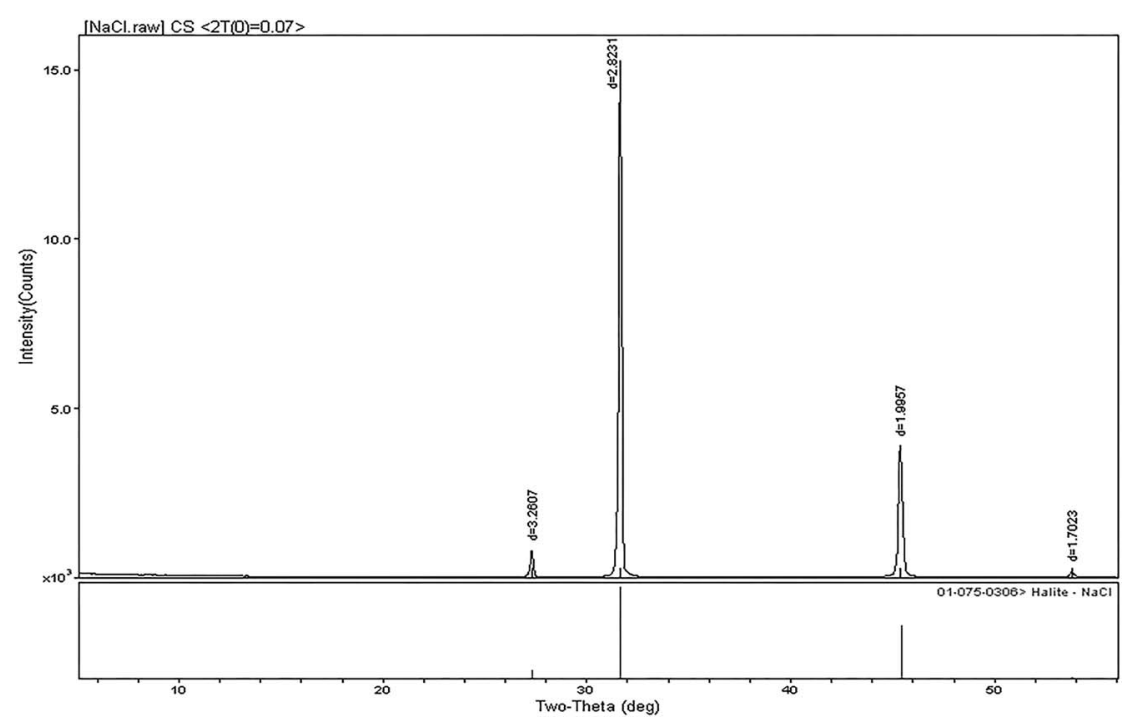

Fig. 3 The X-ray diffraction pattern for $\mathrm{NaCl}$. 
The $\mathrm{NaCl}$ added in the experiment required precombustion. By comparing the combustion at two temperatures $\left(450{ }^{\circ} \mathrm{C}\right.$ and $\left.550{ }^{\circ} \mathrm{C}\right)$, we saw that there was no distinct difference between the two temperatures (Fig. 4). The results of our study suggest that a pre-combustion of $\mathrm{NaCl}$ at $450{ }^{\circ} \mathrm{C}$ ensured that the contaminant content was minimized. We did not find a significant effect of the firing temperature on the $m / z 44$ peak amplitude for the NaCl blanks. However, we did find that the $\mathrm{NaCl}$ placement days was correlated with its blank value. As shown in Fig. 5, the longer the placement time, the larger the $\mathrm{N}_{2} \mathrm{O}$ background value for $\mathrm{NaCl}$. We speculated that this phenomenon might have been due to increased reagent purity reducing other background molecules that interfered with the bacterial conversion of $\mathrm{NO}_{3}{ }^{-}$ into $\mathrm{N}_{2} \mathrm{O}$. Therefore, $\mathrm{NaCl}$ was used immediately on the day of pre-combustion.

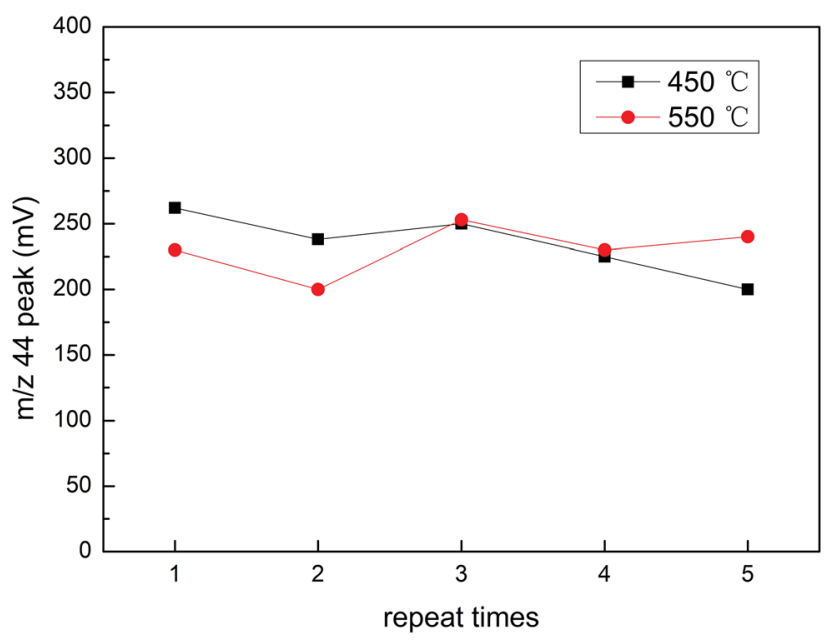

Fig. 4 Correlation between the firing temperature of $\mathrm{NaCl}$ and its $\mathrm{m} / \mathrm{z}$ 44 peak amplitude.

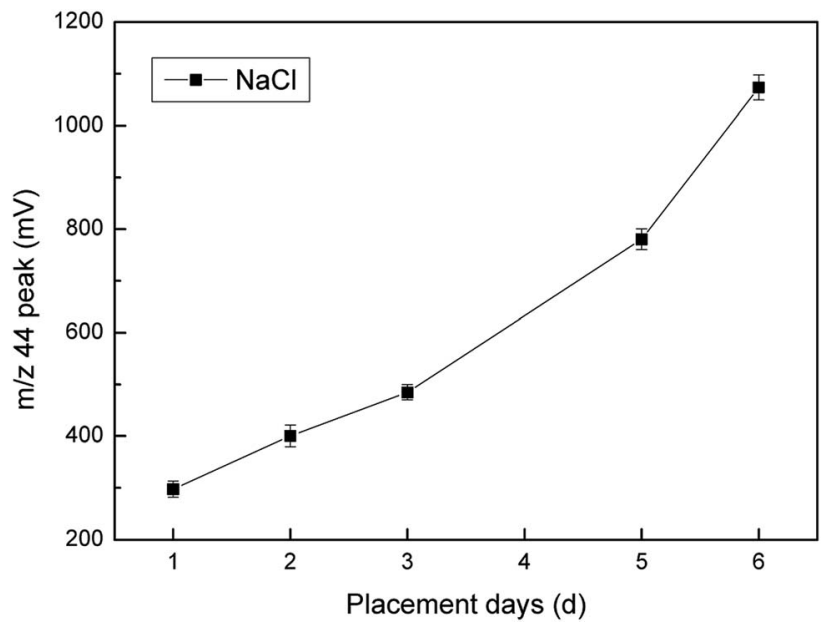

Fig. 5 Correlation between the $\mathrm{NaCl}$ placement days and its $\mathrm{m} / \mathrm{z} 44$ peak amplitude.

\section{$\mathrm{NO}_{3}{ }^{-}$conversion efficiency}

Cadmium powder plays a vital role in the first step of the reduction process as it has the ability to reduce nitrate to nitrite. By changing the amount of $\mathrm{Cd}$ powder added, we found that the $m / z 44$ peak for $\mathrm{NO}_{3}{ }^{-}$and $\mathrm{NO}_{2}{ }^{-}$changed significantly. As the added amount of cadmium powder increased, the peak decreased. More specifically, when the added amount of cadmium powder was less than $0.3 \mathrm{~g}$, the $\mathrm{m} / \mathrm{z} 44$ peak value for $\mathrm{NO}_{3}{ }^{-}$showed no significant changes. However, when it was larger than $0.3 \mathrm{~g}$, the $\mathrm{m} / \mathrm{z} 44$ peak value began to decrease. As the cadmium powder content increased to $1.5 \mathrm{~g}$, the $\mathrm{m} / \mathrm{z} 44$ peak value for $\mathrm{NO}_{3}{ }^{-}$was reduced to zero. The reason, however, for this situation was not that the reduction capacity of the cadmium powder was insufficient. The reduction was too strong due to the excessive cadmium powder content, which further reduced $\mathrm{N}_{2} \mathrm{O}$ to $\mathrm{N}_{2}$, making it impossible to detect in an isotope mass spectrometer. The results showed that $0.3 \mathrm{~g}$ of $\mathrm{Cd}$ powder efficiently reduced the $5 \mathrm{~mL}$ samples from $\mathrm{NO}_{3}{ }^{-}$to $\mathrm{NO}_{2}{ }^{-}$. In addition, the $\mathrm{m} / \mathrm{z} 44$ peak for $\mathrm{NO}_{2}{ }^{-}$also decreased with the addition of Cd powder. These results indicated that the optimal amount of Cd powder was $0.3 \mathrm{~g}$ (Fig. 6).

Based on previous research, in order to eliminate the influence of cadmium powder on the second step in the reduction process, we further explored whether filtration of the supernatant obtained in the first step of the reduction process for cadmium powder would affect the second step of the reduction (Fig. 7). The $m / z 44$ peak values for each substance measured before and after filtration were compared. Then, we found that the results were consistent. Therefore, the supernatant could be used without filtration.

\section{Influence of $\mathrm{NaN}_{3}$}

$\mathrm{NaN}_{3}$ was a key reagent throughout the experiment as it formed an azide buffer with acetic acid and reduced $\mathrm{NO}_{3}{ }^{-}$to $\mathrm{NO}_{2}{ }^{-}$. With the increase in the $\mathrm{NaN}_{3}$ consumption, we found that the $m / z 44$ peak value for $\mathrm{NaNO}_{2}$ increased. However, when the added amount of $\mathrm{NaN}_{3}$ was more than $600 \mathrm{~nm}$, the growth

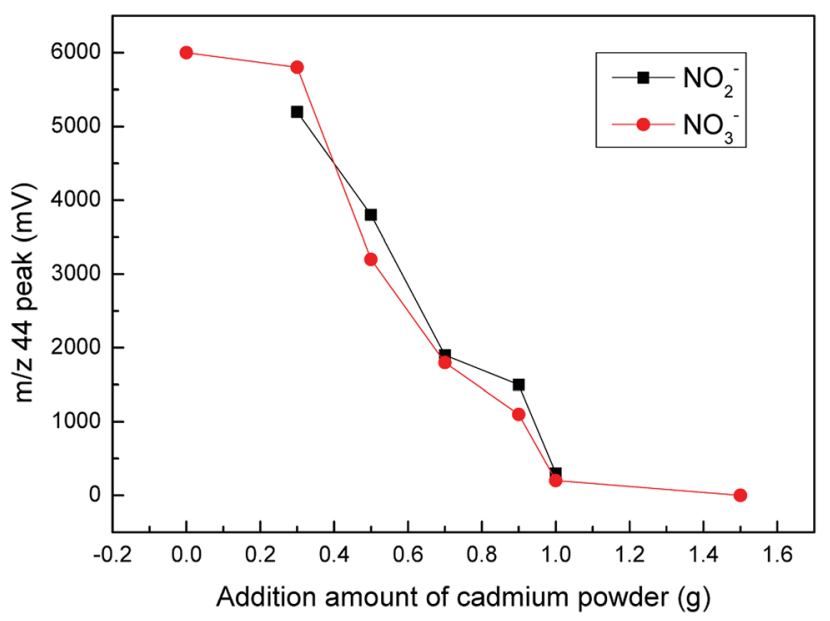

Fig. 6 Relationship between the $\mathrm{m} / \mathrm{z} 44$ peak amplitudes for the $\mathrm{NO}_{3}{ }^{-}, \mathrm{NO}_{2}{ }^{-}$and $\mathrm{Cd}$ powder addition. 


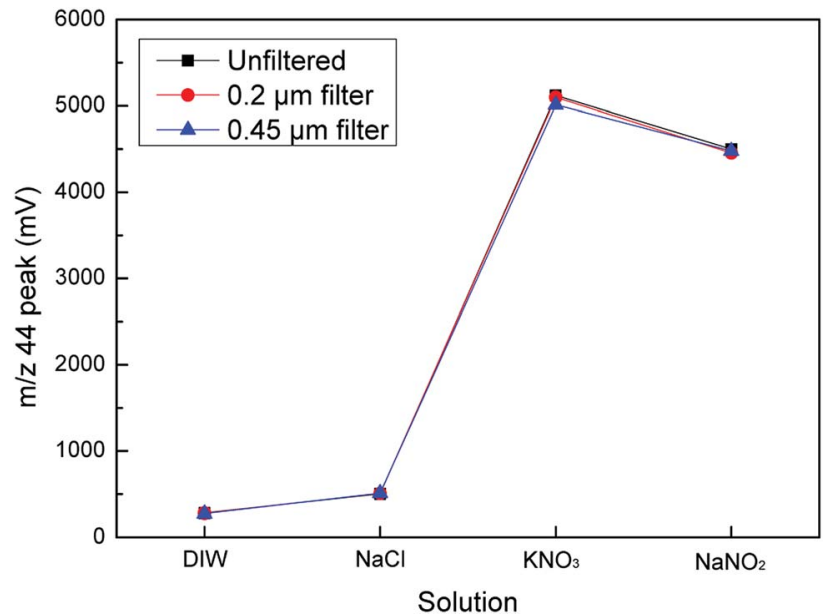

Fig. 7 Effect of the supernatant filtration on the reduction.

range decreased, which meant that the reduction efficiency was not significantly improved (Fig. 8). We could also conclude that $200 \mathrm{nmol}$ of $\mathrm{NaN}_{3}$ could not completely reduce $25 \mathrm{nmol}$ of $\mathrm{NO}_{3}{ }^{-}$. If too much $\mathrm{NaN}_{3}$ is added, it will increase the pollution during the experiment, which may cause unnecessary harm. Therefore, $600 \mathrm{nmol}$ was selected as the best added amount of $\mathrm{NaN}_{3}$. The purge time for $\mathrm{NaN}_{3}$ had an effect on the $m / z 44$ peak value of $\mathrm{NaN}_{3}$ (Fig. 9). The results showed that the measured $\mathrm{m} / \mathrm{z}$ 44 peak value for $\mathrm{NaN}_{3}$ was 261 when the purge time was 0.5 hours. As the purge time increased, the $\mathrm{m} / \mathrm{z} 44$ peak value was lower. However, when the purge time was increased from 1.5 hours to 2 hours, the change in the $m / z 44$ peak was very small. The numerical difference was only 8 . Therefore, we think that 1.5 hours already had a good purge effect. Taking into account the time and cost, we chose 1.5 hours as the best purge time.

\section{Calibration of measurement results}

It can be seen from the above studies that in the process of chemical denitrification, the nitrogen and oxygen isotope

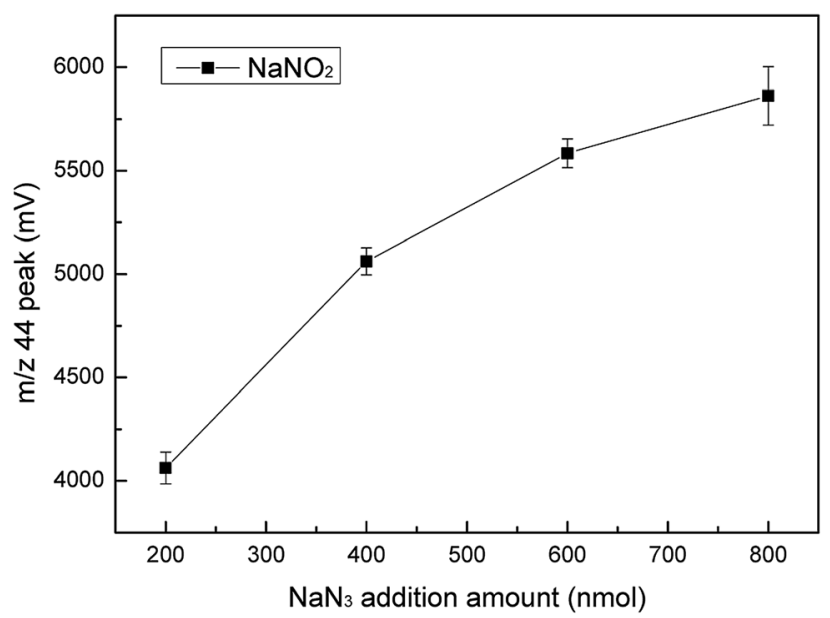

Fig. 8 The $m / z 44$ peak amplitude for $\mathrm{NaNO}_{2}$ changed as the $\mathrm{NaN}_{3}$ usage increased.

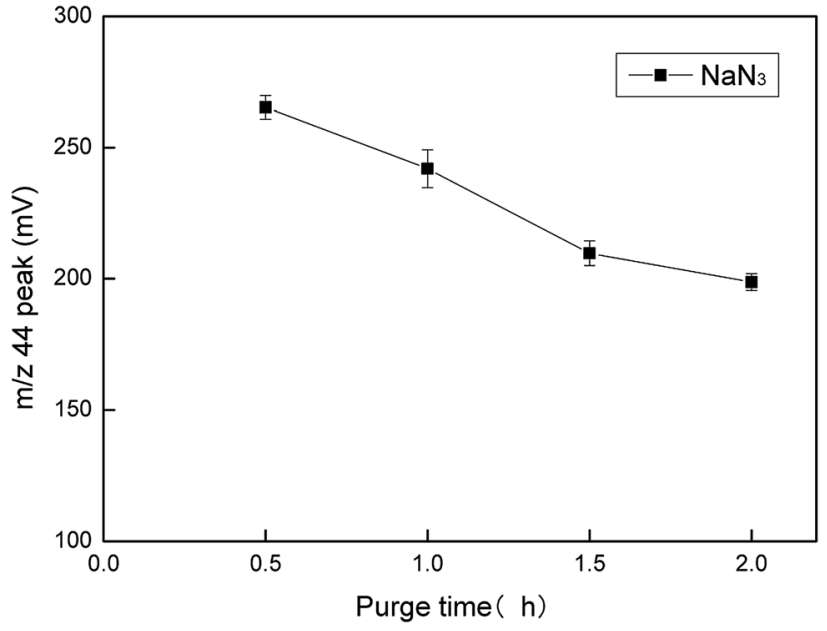

Fig. 9 Effect of the purge time on the $\mathrm{m} / \mathrm{z} 44$ peak amplitude for $\mathrm{NaN}_{3}$.

determination will inevitably produce blank pollution, so we used the standard material solution to prepare the standard curve to correct the measurement results. ${ }^{23}$ Commonly used international standard substances that participate in the calibration curve are USGS-32 $\left(\mathrm{KNO}_{3}\right)$, USGS-34 $\left(\mathrm{KNO}_{3}\right)$, USGS$35\left(\mathrm{NaNO}_{3}\right)$ and IAEA-N3 $\left(\mathrm{KNO}_{3}\right)$. The calibration equation for the $\delta^{15} \mathrm{~N}$ value is: ${ }^{14}$

$$
\delta^{15} \mathrm{~N}_{\mathrm{NO}_{3}{ }^{-} \text {sample }}=\left(\delta^{15} \mathrm{~N}_{\mathrm{N}_{2} \mathrm{O} \text { sample }}-\text { intercept }\right) / \text { slope }
$$

where the intercept and slope were obtained from the linear regression, which was established by the measured $\delta^{15} \mathrm{~N}$ values of the four $\mathrm{NO}_{3}{ }^{-}$standards against the assigned $\delta^{15} \mathrm{~N}$ values.

The standard curve shown in Fig. 10 indicates a good correlation between the measured $\delta^{15} \mathrm{~N}$ value and the true value of $\delta^{15} \mathrm{~N}$. In Table 1, we list the true values and corrected values that passed the standard curve of the four international standard samples. We found that the blank contamination could be calculated and calibrated using the calibration curve. Therefore,

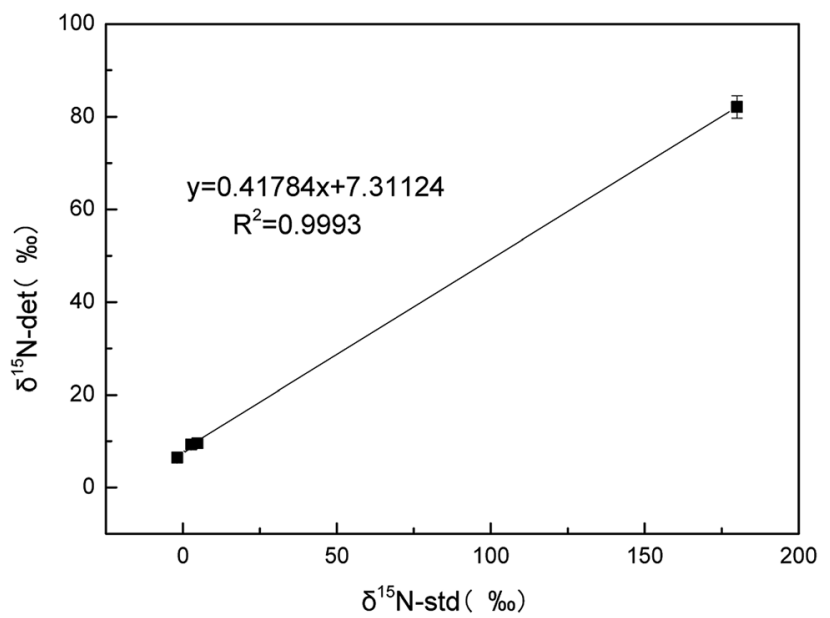

Fig. 10 Linear regression analysis of the measured values and true values for $\delta^{15} \mathrm{~N}$ in four standard substance solutions. 
Table 1 Results from the nitrogen isotope determination of the international standard samples

\begin{tabular}{lccc}
\hline $\begin{array}{l}\text { Standard } \\
\text { sample }\end{array}$ & Standard value (\%) & Calculated value (\%) & RE (\%) \\
\hline USGS-32 & 180 & 185 & 2.7 \\
USGS-34 & -1.8 & -2.0 & 11.1 \\
USGS-35 & 2.7 & 3.3 & 22.2 \\
IAEA-N3 & 4.7 & 5.3 & 12.7
\end{tabular}

during the chemical experiment process, as long as we strictly followed the above measurement conditions, the blank pollution in the experiment could be corrected using the standard curve.

We believe that the chemical conversion method for the determination of nitrogen and oxygen isotopes can more accurately determine the sample.

\section{Conclusion}

This paper presented a relatively simple, highly accurate chemical conversion method (azide method) for the determination of nitrogen and oxygen isotope values in nitrate. Our study revealed the influencing factors for the blank background value in this method and determined the best experimental conditions to improve the reduction conversion efficiency.

By testing the blank background values in the experiment, it was found that $\mathrm{NaCl}$ was the root cause of the fluctuation in the blank value. Then, we explored the cause of the change in the blank value by changing the burning time of $\mathrm{NaCl}$ and the time of placement. We found that a temperature of $450{ }^{\circ} \mathrm{C}$ was sufficient to remove nitrogen impurities. However, $\mathrm{NaCl}$ should be used immediately after burning and should not be added for a long time. After adding $0.3 \mathrm{~g}$ of Cd powder and $600 \mathrm{nmol}$ of $\mathrm{NaN}_{3}, \mathrm{NO}_{3}{ }^{-}$was completely reduced and the reduction effect was better.

Afterwards, we plan to apply this method to practical measurements, which can be used to measure nitrogen sources in soil and rivers.

\section{Conflicts of interest}

There are no conflicts to declare.

\section{Acknowledgements}

This work was sponsored by the National Natural Science Foundation of China (21706038), State Key Laboratory of Loess and Quaternary Geology (SKLLQGYQ1802) and the National Training Projects of the University Students' Innovation and Entrepreneurship Program (201910710124, 201910710125 and s201910710244).

\section{Notes and references}

$1 \mathrm{X}$. Liu, Y. Zhang, W. Han, et al., Enhanced nitrogen deposition over China, Nature, 2013, 494(7438), 459-462.

2 J. Liu, B. Peng, Z. Xia, et al., Different fates of deposited $\mathrm{NH}_{4}{ }^{+}$ and $\mathrm{NO}_{3}{ }^{-}$in a temperate forest in northeast China: a ${ }^{15} \mathrm{~N}$ tracer study, Glob. Chang. Biol., 2017, 23(6), 2441-2449.

3 E. Minet, C. E. Coxon, R. Goodhue, et al., Evaluating the utility of ${ }^{15} \mathrm{~N}$ and ${ }^{18} \mathrm{O}$ isotope abundance analyses to identify nitrate sources: a soil zone study, Water Res., 2012, 46(12), 3723-3736.

4 M. M. M. Kuypers, H. K. Marchant and B. Kartal, The microbial nitrogen-cycling network, Nat. Rev. Microbiol., 2018, 16(5), 263-276.

5 M. Zhang, J. Shi and L. Wu, Factors influencing the accuracy of the denitrifier method for determining the oxygen isotopic composition of nitrate, J. Zhejiang Univ., Sci., B, 2019, 20(1), 49-58.

6 Y. Chang, X. Liu, C. Deng, et al., Source apportionment of atmospheric ammonia before, during, and after the 2014 APEC summit in Beijing using stable nitrogen isotope signatures, Atmos. Chem. Phys., 2016, 16, 11635-11647.

7 Y. Fang, K. Koba, X. Wang, et al., Anthropogenic imprints on nitrogen and oxygen isotopic composition of precipitation nitrate in a nitrogen-polluted city in southern China, Atmos. Chem. Phys. Discuss., 2011, 10(9), 1313-1325.

8 L. Geng, B. Alexander, J. Cole-Dai, et al., Nitrogen isotopes in ice core nitrate linked to anthropogenic atmospheric acidity change, Proc. Natl. Acad. Sci. U. S. A., 2014, 111(16), 5808-5812.

9 M. I. Makarov, The nitrogen isotopic composition in soils and plants: its use in environmental studies (a review), Eurasian Soil Sci., 2009, 42(12), 1335-1347.

10 Y. Takebayashi, K. Koba, Y. Sasaki, et al., The natural abundance of ${ }^{15} \mathrm{~N}$ in plant and soil-available $\mathrm{N}$ indicates a shift of main plant $\mathrm{N}$ resources to $\mathrm{NO}_{3}{ }^{-}$from $\mathrm{NH}_{4}{ }^{+}$along the $\mathrm{N}$ leaching gradient, Rapid Commun. Mass Spectrom., 2010, 24, 1001-1008.

11 B. Yang, H. Wang, Y. Jiang, et al., Combing $\delta^{15} \mathrm{~N}$ and $\delta^{18} \mathrm{O}$ to identify the distribution and the potential sources of nitrate in human-impacted watersheds, Shandong, China, RSC Adv. , 2018, 8, 23199-23205.

12 P. Lachouani, A. H. Frank and W. Wanek, A suite of sensitive chemical methods to determine the $\delta^{15} \mathrm{~N}$ of ammonium, nitrate and total dissolved $\mathrm{N}$ in soil extracts, Rapid Commun. Mass Spectrom., 2010, 24(24), 3615-3623.

13 M. R. McIlvin and M. A. Altabet, Chemical Conversion of Nitrate and Nitrite to Nitrous Oxide for Nitrogen and Oxygen Isotopic Analysis in Freshwater and Seawater, Anal. Chem., 2005, 77(17), 5589-5595.

14 Y. Tu, Y. Fang, D. Liu, et al., Modifications to the azide method for nitrate isotope analysis, Rapid Commun. Mass Spectrom., 2016, 30(10), 1213-1222.

15 E. Ryabenko, M. A. Altabet and D. W. R. Wallace, Effect of chloride on the chemical conversion of nitrate to nitrous oxide for $\delta^{15} \mathrm{~N}$ analysis, Limnol. Oceanogr.: Methods, 2009, $7(7), 545-552$. 
16 M. D. Bell and J. O. Sickman, Correcting for background nitrate contamination in $\mathrm{KCl}$-extracted samples during isotopic analysis of oxygen and nitrogen by the denitrifier method, Rapid Commun. Mass Spectrom., 2014, 28(5), 520526.

17 D. J. Ma, Z. Y. Chen and L. Yi, Development of improved dual-diazonium reagents for faster crosslinking of tobacco mosaic virus to form hydrogels, RSC Adv., 2019, 9(50), 29070-29077.

18 U. Tsunogai, T. Kido, A. Hirota, et al., Sensitive determinations of stable nitrogen isotopic composition of organic nitrogen through chemical conversion into $\mathrm{N}_{2} \mathrm{O}$, Rapid Commun. Mass Spectrom., 2008, 22(3), 345-354.

19 M. Mcilvin and M. Altabet, Nitrogen and Oxygen Isotopic Detection of Nitrate in Seawater by Chemical Conversion of Nitrate to Nitrous Oxide, J. Chem. Technol. Biotechnol., 2018, 3(1), 1216-1223.

20 D. Liu, Y. Fang, Y. Tu, et al., Chemical Method for Nitrogen Isotopic Analysis of Ammonium at Natural Abundance, Anal. Chem., 2014, 86(8), 3787-3792.

21 S. Dai, L. Xie, L. Peng, et al., Determination of nitrogen and oxygen isotopes in nitrates: a minireview, Anal. Lett., 2017, 50(13), 2045-2057.

22 Y. Zhang, B. C. Cheng, C. Li, et al., Characterization and comparison of Re-Du-Ning aerosol particles generated by different jet nebulizers, RSC Adv., 2019, 9, 30292-30301.

23 L. Rock and B. H. Ellert, Nitrogen-15 and oxygen-18 natural abundance of potassium chloride extractable soil nitrate using the denitrifier method, Soil Sci. Soc. Am. J., 2007, 71(2), 355-361. 